\title{
Biosynthesis of Silver Nanoparticles by Using Invasive Caulerpa cylindracea Sonder
}

\author{
Yesim Yilmaz Abeska1 ${ }^{1}$, Levent Cavas ${ }^{1,2, *}$ (D)
}

${ }^{1}$ Dokuz Eylül University, The Graduate School of Natural and Applied Sciences, Department of Biotechnology, 35390 İzmir, Turkey.

${ }^{2}$ Dokuz Eylül University, Faculty of Science, Department of Chemistry, 35390 İzmir, Turkey.

\section{How to cite}

Abeska, Y.Y., Cavas, L. (2021). Biosynthesis of Silver Nanoparticles by Using Invasive Caulerpa cylindracea Sonder. Turkish Journal of Fisheries and Aquatic Sciences, 21, 451-463. http://doi.org/10.4194/1303-2712-v21_9_04

\section{Article History}

Received 24 November 2020

Accepted 28 May 2021

First Online 31 May 2021

\section{Corresponding Author}

Tel.: +902323018701

E-mail: levent.cavas@deu.edu.tr

\section{Keywords}

Artificial neural network

Caulerpa cylindracea

Green synthesis

Silver nanoparticles

\begin{abstract}
Caulerpa cylindracea is an invasive seaweed in the Mediterranean Sea. In this study, we propose an alternative method to utilise the biomass of $C$. cylindracea to synthesize silver nanoparticles (AgNPs). UV-VIS spectroscopy, FT-IR and X-ray diffraction were used in characterization steps. The results show that optimum conditions such as time, initial concentration of $\mathrm{AgNO}_{3}$ and temperature were found to be $240 \mathrm{~min}, 0.1 \mathrm{M}$ $\mathrm{AgNO}_{3}$ and $85^{\circ} \mathrm{C}$, respectively. The measured particle size of the synthesized AgNPs were $22 \mathrm{~nm}$. Since AgNPs were encapped by the secondary metabolites of C. cylindracea, the synthesized AgNPs showed stable solubility in aqueous conditions. The experimental data related to synthesis of AgNPs were modelled by using artificial neural network (ANN). Agitation time and rate, temperature, $\mathrm{pH}$, concentration of AgNO3 and extract were chosen as input and absorbance values were chosen as output. ANN modelling study exhibited that Bayesian regularization backpropagation, scaled conjugate gradient backpropagation and Levenberg-Marquardt backpropagation algorithms better modelled the experimental data compared to studied 11 backpropagation algorithms. In conclusion, biomass of invasive seaweeds can be used to synthesize AgNPs for commercial use and this will bring a new perspective to utilisation of the biomass of invasive seaweeds. A possible economical value may create a stress on the spread of these alien species in the Mediterranean Sea.
\end{abstract}

\section{Introduction}

Nanotechnology has been significantly affecting our daily lives for the last decade. Various nano-based industrial products are currently being used. Conspicuous mechanical and optical properties of nanoparticles are responsible for the growing attention to its application in catalysis (Jia \& Schüth, 2011), medicine (Martinez-Gutierrez et al., 2010), cosmetics (Sakulwech et al., 2018), UV blocker (Shi et al., 2012), material science (Dodoo-Arhin et al., 2020) and other allied industrial areas. Although nanomaterials' unique properties make them appealing to engineering industries, formation of hazardous intermediates during their traditional synthesis raises concern (Kharissova et al., 2013). On the other hand, green synthesis methods are eco-friendly, cost effective, simple and the production can be scaled up to meet commercial needs. Green synthesis methods will continue to gain impulsion in the upcoming years due to rising environmental concerns and awareness. In the scientific literature, there is an increasing trend related to the synthesis of 
nano-materials such as silver, gold, cerium and palladium by using green synthesis methods (Sharma et al., 2009; Philip, 2010; Arumugam et al., 2015; Nadagouda \& Varma, 2008).

Many different biomasses can be used to biosynthesize nano-materials. Algae, mushroom, pine, microorganisms and plants are current biomasses in the literature (González-Ballesteros et al., 2018; Sen et al., 2013; Niu et al., 2020; Singh et al., 2016; Katta \& Dubey, 2020). In our paper, we selected to study Caulerpa cylindracea Sonder. The aim of selection of this species is to evaluate the biomass since it is one of the wellknown invasive species in the history of the Mediterranean Sea (Klein \& Verlaque, 2008). The invasion by $C$. cylindracea has been continuing since 1991 and still there has been no scientific publication yet in the literature to eradicate the invasion or reduce the negative effects of this species. It is very important to note that many negative effects of $C$. cylindracea on the indigenous species have previously been reported (Piazzi \& Balata, 2008; Vázquez-Luis et al., 2008; Cavas \& Pohnert, 2010; Bernardeau-Esteller et al., 2020). Therefore, this paper proposes an alternative method for the utilisation of biomass of invasive $C$. cylindracea off the İzmir coastlines.

Many compounds from marine organisms are used as industrial and biotechnological products. In recent years, marine organisms have been used in also nanoparticle synthesis. Since the conditions of the marine ecosystem are quite different compared to land, bioactive compounds of marine plants may have dissimilarities (Ravikumar et al., 2010).

Algae are highly suitable for green synthesis owing to high metal deposition capabilities (Davis et al., 2003). Algae contain polysaccharides such as alginate, fucoidan; polyphenols, proteins, vitamins and minerals in their structure (Kushnerova et al., 2010; Mizuno et al., 2009). Silver (Kathiraven et al., 2015), gold (Singh et al., 2013), palladium (Momeni \& Nabipour, 2015), platinum (Ramkumar et al., 2017), cadmium sulphide (Rao \& Pennathur, 2017), copper oxide (Abboud et al., 2014), iron oxide nanoparticles (Mahdavi et al., 2013) which have different size and morphology were synthesized using algae extracts.

Since different biomolecules and redox systems work in the reduction of metal ions, the mechanism has not yet been fully explained. There are also differences in the mechanisms of intracellular and extracellular synthesis of nanoparticles. The formation of algal metallic nanoparticles involves independent biosorption of metabolites on the cell surface and subsequent aggregation of metal nanoparticles (Chakraborty et al., 2006; Wang \& Chen, 2009; Barwal et al., 2011; Shankar et al., 2016). The synthesis of metal nanoparticles is affected by the changes in $\mathrm{pH}$, mixing, temperature, extract and metal ion concentration. According to Chakraborty et al. (2006), enzymes found in algal cells perform as reducing agents and play a role in the nucleation and growth of metal nanoparticles. Since synthesis of AgNPs is needed to optimise many different parameters such as temperature, initial silver nitrate concentration, mixing rate and $\mathrm{pH}$, it would be better to use a modelling system to find optimum conditions and also model the experimental values. Even if many modelling methods are available in the scientific literature, artificial intelligence (AI) based methods show superiority. Al has been developed in recent years and it is now an important part of our daily lives. Al applications are commonly used in information technologies including mobile phones and apps. One of the Al applications is an artificial neural network (ANN). ANN has many superiorities over traditional modelling methods. Also, ANN provides an important contribution to the understanding of complex situations including non-linear systems. ANN has so far been used in the estimation of retention time in HPLC (Mert et al., 2014), development and validation of anti-cancer drugs (Pivetta et al., 2013), drug discovery (Mandlik et al., 2016), diagnosis tool for tuberculosis and (Dande \& Samant, 2018), diagnosis of osteoporosis (Yu et al., 2016). ANN has attracted a wide range of scientists from different fields. ANN can solve the problems based on unknown relationships among the data. Based on training, validation and testing steps, ANN develops a learning process and then it generalizes the knowledge for prediction of the response (Pivetta et al., 2013).

In the present study, AgNPs were synthesized by using invasive marine algae, $C$. cylindracea, from the Mediterranean Sea. The synthesized AgNPs were characterized and the optimisation data were modelled through ANN. To our knowledge, this is the first scientific investigation related to the use of biomass of an invasive seaweed to synthesize AgNPs.

\section{Materials and Methods}

\section{Materials}

Silver nitrate was purchased from Macron Fine Chemicals and deionized water used in experiments was obtained from ELGA model OS007XXM1. pH meter and IKA RCT basic IKAMAG ${ }^{\circledR}$ shaker were used in the synthesis procedure. C. cylindracea was collected from Dikili and Çeşme, İzmir via freediving from up to -5 meters of depth. After collection, $C$. cylindracea sample was washed and then dried under the sunlight and ground. The average particle diameter of the ground sample was found as $500 \mu \mathrm{m}$. The data related to the synthesis of AgNPs were modelled by using the neural networks toolbox of MATLAB (R2016b).

\section{Preparation of Caulerpa cylindracea Extract}

Ground C. cylindracea sample was extracted with the method of Edison et al. (2016) and Kathiraven et al. (2015). The extraction concentrations were chosen as $0.001 \mathrm{~g} / \mathrm{ml}, 0.01 \mathrm{~g} / \mathrm{ml}$ and $0.075 \mathrm{~g} / \mathrm{ml}$. Previously, Edison et al. (2016) and Kathiraven et al. (2015) proposed the 
methods to extract Caulerpa spp for the synthesis of AgNPs. The joint parts of their methods are to add $1 \mathrm{~g}$ Caulerpa samples into $20 \mathrm{~mL}$ deionised water after washing and drying protocols. Edison et al. (2016) applied $80^{\circ} \mathrm{C}$ for $30 \mathrm{~min}$. However, Kathiraven et al. (2015) kept their samples at room temperature for 24 hours. In this study, in addition to the above mentioned protocols, C. cylindracea samples were washed, dried and then ground. After the solution stayed at $80^{\circ} \mathrm{C}$ for one-hour, the solution was filtered via Whatman 40 filter paper. As summary, three extraction protocols are applied and they are A) $24 \mathrm{~h}$ at $25^{\circ} \mathrm{C}$, B) $30 \mathrm{~min}$ at $80^{\circ} \mathrm{C}$ and, C) $1 \mathrm{~h}$ at $80^{\circ} \mathrm{C}$. The values are the means of three different experiment. For statistical comparison, Microsoft excel (t-test) was used and statistical significance was set at $\mathrm{p}=0.05$.

\section{The Synthesis of Silver Nanoparticles Via C. cylindracea}

The concentration of $C$. cylindracea extract and $\mathrm{AgNO}_{3}$ solution, $\mathrm{pH}$, temperature, agitation time and agitation rate were studied for optimization of AgNPs synthesis. For the initial synthesis of AgNPs, the solution including $10 \mathrm{ml}$ of $C$. cylindracea extract, $10 \mathrm{ml} 0.001 \mathrm{M}$ $\mathrm{AgNO}_{3}$ solution and $30 \mathrm{ml}$ deionized water were mixed. The colour of this solution was light yellow, after 20 minutes of agitation the colour turned into reddish brown. This colour change indicates the formation of AgNPs. The synthesized AgNPs were separated via centrifugation at $10,000 \mathrm{rpm}$ for 30 minutes. Table 1 shows the statistics of the data for the optimization process for $C$. cylindracea based AgNPs. The values are the means of three different experiment. For statistical comparison, Microsoft excel (t-test) was used and statistical significance was set at $p=0.05$.

\section{The Characterization of Synthesized Silver Nanoparticles}

The most important and easy characterization of AgNPs is via UV-VIS spectrum. The synthesis process of AgNPs can easily be followed by UV-VIS spectrophotometry (Shimadzu UV-1801 UV-VIS spectrophotometer).

BioTek Microplate Reader was also used for optimization experiments. The Fourier transform infrared (FT-IR) spectrometry was used to define the surface characteristics of the extract and synthesized nanoparticles. FT-IR was carried out for the biosynthesized AgNPs and Caulerpa sample. $100 \mathrm{mg}$ of $\mathrm{KBr}$ powder and $1 \mathrm{mg}$ of synthesized AgNPs were mixed and pellets were prepared. The X-ray diffraction (XRD) analysis was carried out to identify the crystallographic quality of the synthesized AgNPs. Thermo Scientific ARL $X^{\prime}$ TRA was used for analysis. The analysis was performed between 5-90 degree angles with 2 degrees/minute scan rate and using $\mathrm{Ni}$-filtered $\mathrm{CuK} \alpha$ radiation.

\section{Artificial Neural Network Study}

The input parameters in these networks were agitation time, agitation rate, temperature, $\mathrm{pH}, \mathrm{AgNO}_{3}$ concentration and extract of C. cylindracea concentration. The output data was absorbance value. Before creating the network, the hidden neuron number was optimized under default settings of MATLAB. The MSE and $R^{2}$ values were obtained from MATLAB. Training, validation and testing data were selected randomly by MATLAB for network creation. Total numbers of data were 126 and 111 data were chosen for training, testing and validation in ANN modelling. Moreover, training, validation and test percentages were examined. Percentages, which had the highest $R^{2}$ and the lowest mean square error (MSE) values, were selected for ANN design. Hidden neuron numbers were studied using default settings which were $70 \%, 20 \%$ and $5 \%$ of datasets for training, validation and testing. 15 of the 126 data were selected as sample parameters for using after ANN optimization as estimating data. Best performance parameters were obtained with testing 11 different back propagation algorithms.

\section{Results}

\section{Synthesis Parameters}

As described in the material and method section, three different methods were performed for the extraction of $C$. cylindracea sample. According to Figure 1 , the highest absorbance value was found for the procedure of Edison et al. (2016), absorbance value was found as a 0.178 after 240 minutes. There were

Table 1. Statistics of the data for the optimization process for Caulerpa cylindracea based silver nanoparticles synthesis.

\begin{tabular}{lccccc}
\hline$\left[\mathrm{AgNO}_{3}\right], \mathrm{M}$ & {$[$ Caulerpa cylindracea], $\mathrm{g} / \mathrm{ml}$} & Temperature, ${ }^{\circ} \mathrm{C}$ & $\mathrm{pH}$ & Agitation rate & Agitation time \\
\hline 0.0010 & 0.001 & 25 & 3.0 & 0 & $0-360 \mathrm{~min}$ \\
0.0025 & 0.010 & 40 & 4.5 & 200 & \\
0.0050 & 0.075 & 55 & 6.0 & 300 \\
0.0075 & & 70 & 7.5 & 400 \\
0.0100 & & 85 & 9.0 & & \\
0.0250 & & & & & \\
0.0500 & & & & & \\
0.0750 & & & & & \\
0.1000 & & & & & \\
0.2000 & & & & & \\
\hline
\end{tabular}




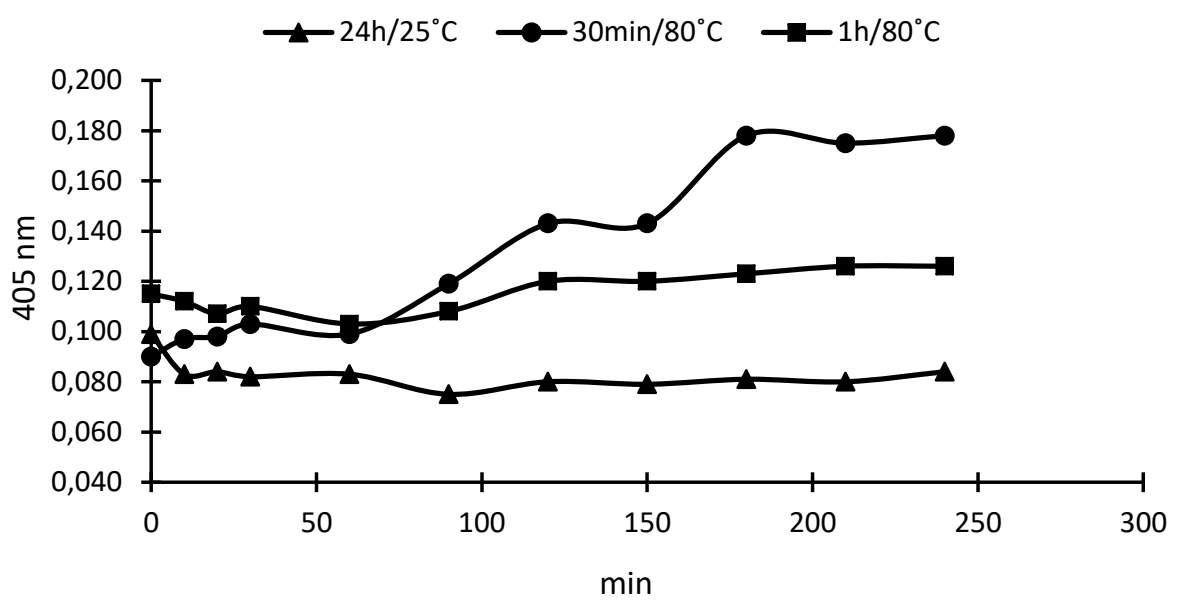

Figure 1. Effect of different extraction protocols $\left(24 \mathrm{~h} / 25^{\circ} \mathrm{C}, 30 \mathrm{~min} / 80^{\circ} \mathrm{C}, 1 \mathrm{~h} / 80^{\circ} \mathrm{C}\right)$ for Caulerpa cylindracea on silver nanoparticles synthesis $\left(\mathrm{pH}=6.50\right.$, Temperature $=60^{\circ} \mathrm{C}$, Caulerpa cylindracea concentration $=0.02 \mathrm{~g} / \mathrm{mL},\left[\mathrm{AgNO}_{3}\right]=0.001 \mathrm{M}$, Agitation rate $=0 \mathrm{rpm}$ ). The values are the means of three different experiments.

fluctuations in the diagram after 60-minutes, absorbance values for $30 \mathrm{~min} / 80^{\circ} \mathrm{C}$ increased drastically. Absorbance values of other extraction protocols did not change significantly in comparison with $30 \mathrm{~min} / 80^{\circ} \mathrm{C}$. For $1 \mathrm{~h} / 80^{\circ} \mathrm{C}$, the highest absorbance value was found as 0.126 at $240 \mathrm{~min}$ and for $24 \mathrm{~h} / 25^{\circ} \mathrm{C}$ the highest absorbance value was 0.09 in the beginning. At $240 \mathrm{~min}$ the samples incubated at $30 \mathrm{~min} / 80^{\circ} \mathrm{C}$ are statistically $(p<0.05)$ higher than those of other samples incubated $24 \mathrm{~h} / 25^{\circ} \mathrm{C}$ and $1 \mathrm{~h} / 80^{\circ} \mathrm{C}$.

$0.001,0.01$ and $0.075 \mathrm{~g} / \mathrm{ml}$ values were chosen for optimization of extract concentration. In our work, we observed that absorbance values of synthesized AgNPs increased when extract concentration increased. This can be seen in Figure 2. The samples which C. cylindracea extract concentration was $0.075 \mathrm{~g} / \mathrm{ml}$ had higher absorbance value and statistically $(p<0.05)$ significant.

The effect of time on the synthesis of AgNPs was studied in the range of $0-390$ minute. There were fluctuations at absorbance values and the experiment time was chosen as 240 minutes because the highest absorbance value was 0.082 at this point. The reaction time required for the synthesis of stable nanoparticles is given in the literature in the range of 1 to 6 hours and as the duration increased, the intensity of the UV absorption peaks increased (Mahiuddin et al., 2020; Darroudi et al., 2011).

To study the effects of initial $\mathrm{AgNO}_{3}$ concentrations on the synthesis of AgNPs, different $\mathrm{AgNO}_{3}$ concentrations were studied. According to Figure 3 , the highest absorbance value was found to be 0.206 at 0.1 $\mathrm{M} \mathrm{AgNO}_{3}$. Under the light of Figure 3, it is seen that when the concentration of $\mathrm{AgNO}_{3}$ rises, the absorbance value of synthesized AgNPs also rises. The samples incubated at $0.1 \mathrm{M}$ are statistically $(\mathrm{p}<0.05)$ higher than those of other samples. The initial concentration of metal salt in the medium is related to the average size of the nanoparticles, and the increase in concentration causes the nanoparticles to increase in size. This is related to the high surface area per unit volume for $\mathrm{AgNO}_{3}$ (Janardhanan et al., 2009; Ajitha et al., 2013; Htwe et al., 2019).

For the optimization of green synthesis of AgNPs related to the temperature, the experiments at different temperatures were carried out. The temperature values were chosen in the range of $25-85^{\circ} \mathrm{C}$ and the highest absorbance value was found as a 0.623 at $85^{\circ} \mathrm{C}$. According to Figure 4, there is a sharp increase at $55^{\circ} \mathrm{C}$ and it reaches to the equilibrium after $70^{\circ} \mathrm{C}$. The samples incubated at $85^{\circ} \mathrm{C}$ are statistically $(\mathrm{p}<0.05)$ higher than those of other samples incubated $25^{\circ} \mathrm{C}, 40^{\circ} \mathrm{C}, 55$ and $70^{\circ} \mathrm{C}$. The reaction rate increases with increasing temperature, and the size of nanoparticles decreases (Fayaz et al., 2009; Khalil et al., 2014). According to Liu et al. (2020), when sufficient $\mathrm{Ag}^{+}$ions are present in the environment, rising temperature values cause an increase in nucleation rate and growth rate.

The effect of $\mathrm{pH}$ values was examined in the $\mathrm{pH}$ range of 3-10. The highest absorbance value was found to be 1.727 at $\mathrm{pH} 10.5$ and the colour of the experiment solution was turned to yellow to very dark colour as $\mathrm{pH}$ values increased. The shape and size of biosynthesized silver nanoparticles can be manipulated by changes in $\mathrm{pH}$ values (Khalil et al., 2014). The $\mathrm{pH}$ value of the environment also affects the stabilizing and capping properties of the metabolites coming from the extract as a result of affecting the charge of the molecules (Khalil et al., 2014; Mahiuddin et al., 2020). As the pH of the reaction medium increases, the nanoparticle size decreases so optimum range is neutral or basic $\mathrm{pH}$ values (Sathishkumar et al., 2009; Mahiuddin et al., 2020).

Agitation rate is one of the parameters for the synthesis of AgNPs nanoparticles. There is an increasing trend with the rising agitation rate. The highest absorbance value was 2.928 at $400 \mathrm{rpm}$. We observed the absorbance value higher than 1 because of the 


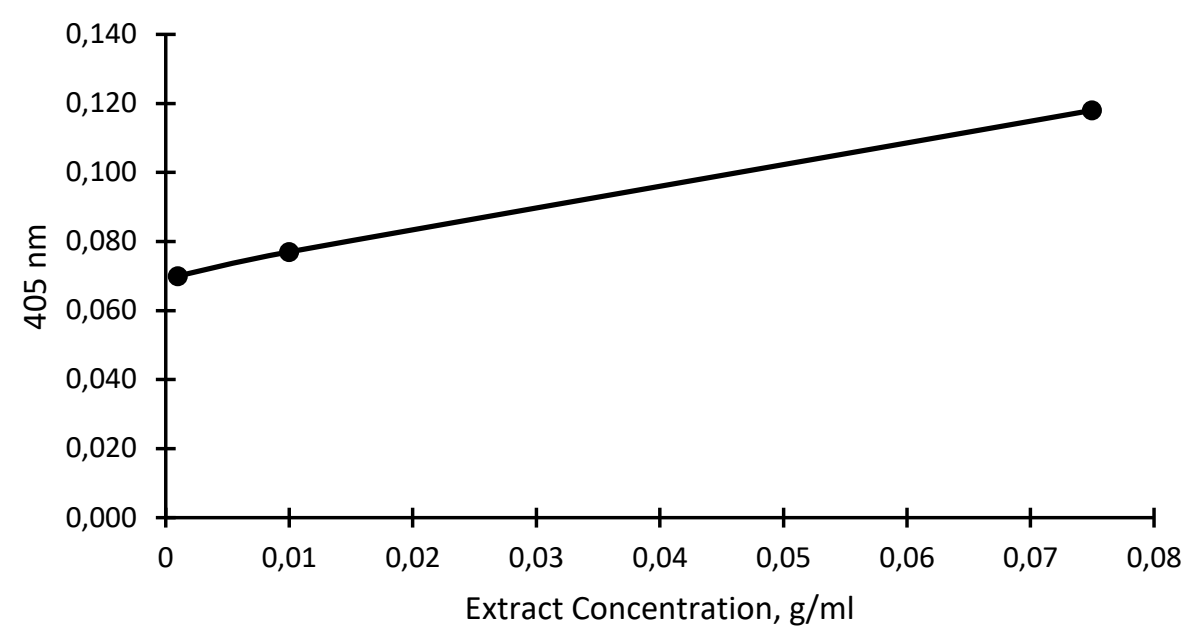

Figure 2. Effect of Caulerpa cylindracea extract concentration on the silver nanoparticles synthesis $\left(\mathrm{pH}=6.5, \mathrm{Temperature}=25^{\circ} \mathrm{C}\right.$, $\left[\mathrm{AgNO}_{3}\right]=0.001 \mathrm{M}$, Agitation rate $=0 \mathrm{rpm}$ ). The values are the means of three different experiments.

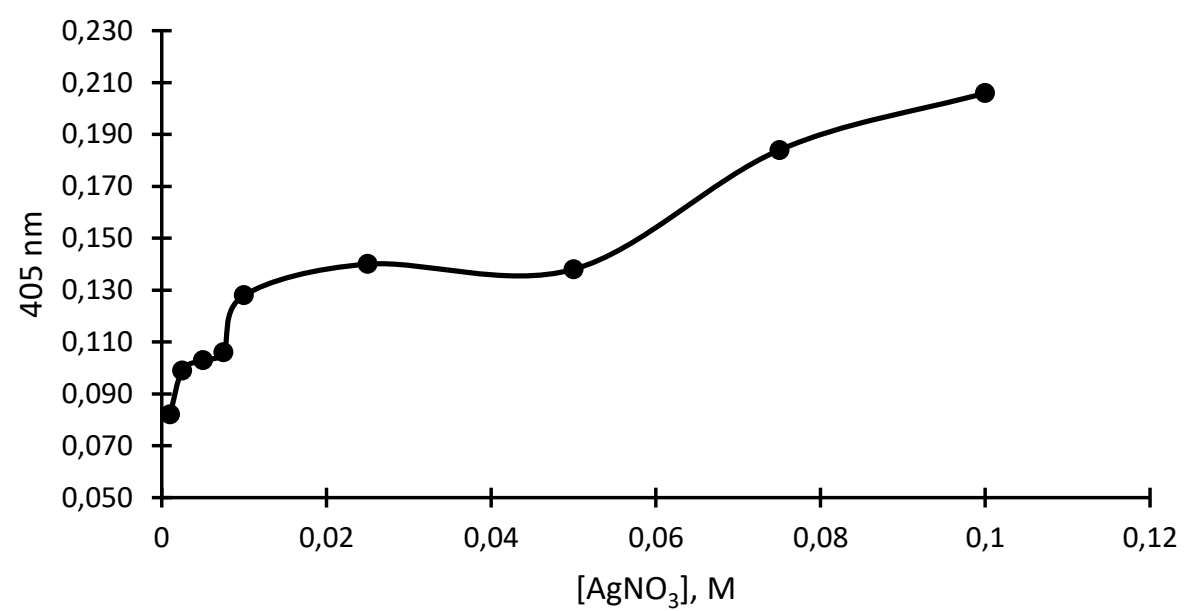

Figure 3. Effect of different $\mathrm{AgNO}_{3}$ concentrations on silver nanoparticles synthesis (Caulerpa cylindracea concentration $=0.01 \mathrm{~g} / \mathrm{mL}, \mathrm{pH}=6.00$, Temperature $=25^{\circ} \mathrm{C}$, Agitation rate $=0 \mathrm{rpm}$, Agitation time $=240 \mathrm{~min}$ ). The values are the means of three different experiments.

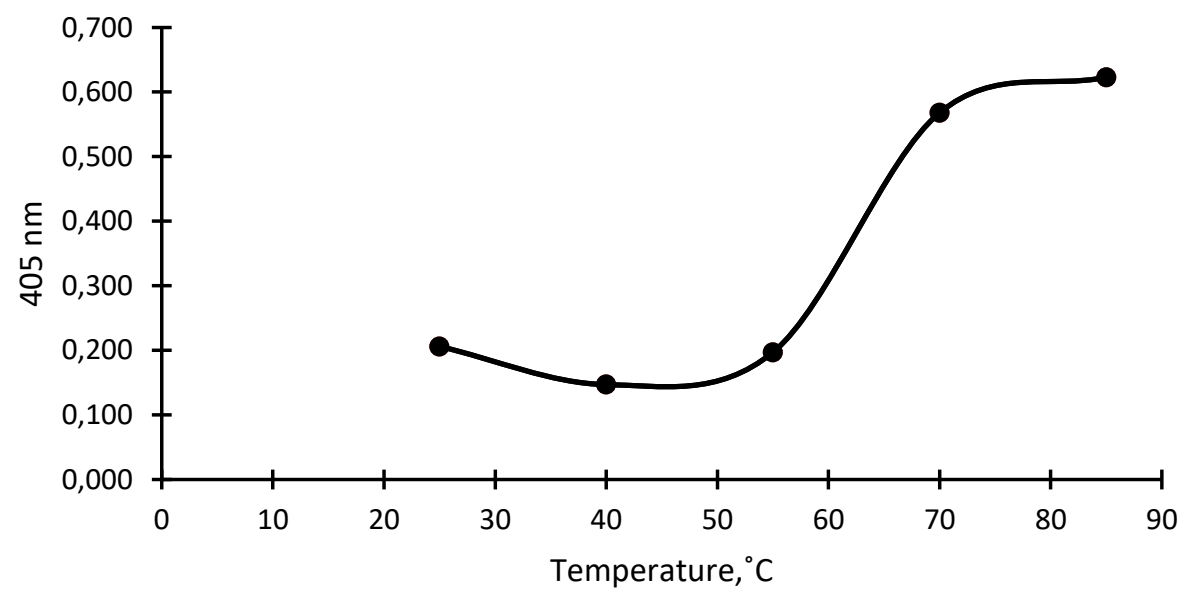

Figure 4. Effect of different temperature values on silver nanoparticles synthesis $\left(\left[\mathrm{AgNO}_{3}\right]=0.1 \mathrm{M}\right.$, Caulerpa cylindracea concentration $=0.01 \mathrm{~g} / \mathrm{mL}, \mathrm{pH}=6.00$, Agitation rate $=0 \mathrm{rpm}$, Agitation time $=240 \mathrm{~min}$ ). The values are the means of three different experiments. 
increased synthesis of AgNPs. Although it shifted from the Lambert-Beer Law, we wanted to show this value for an increased concentration of AgNPs in the solution.

\section{Characterization}

The synthesized AgNPs were characterized by using UV-Vis Spectrophometry, XRD and FT-IR. The UVVIS spectrum of the synthesized AgNPs is given in the Figure 5. We observed very characteristic peaks in the spectrum. Max absorbance value was seen at $445 \mathrm{~nm}$. The results are well in line with the published reports (Kathiraven et al., 2015; Edison et al., 2016). Figure 5 also reveals that agitation time increases the synthesis of AgNPs.

Surface active functional groups in the synthesized AgNPs were characterized by FT-IR methodology in the range of $400-4000 \mathrm{~cm}^{-1}$. We wanted to give FT-IR graphs of the raw $C$. cylindracea and also $C$. cylindracea based AgNPs to see the functional groups. From the Figure 6, it could be said that secondary metabolites such as caulerpin and caulerpenyne, could be effective in the synthesis of AgNPs. The effect of caulerpenyne in the synthesis of AgNPs was previously proposed by Aboelfetoh et al. 2017. The peak at the $3416 \mathrm{~cm}^{-1}$ and $3436 \mathrm{~cm}^{-1}$ may be attributed to $-\mathrm{OH}$ stretching in proteins, polysaccharides or polyphenols (Song et al., 2009). The peaks observed at $2939 \mathrm{~cm}^{-1}$ and $2967 \mathrm{~cm}^{-1}$ could be related with $\mathrm{CH}$ stretching of alkanes. A small band at $1629 \mathrm{~cm}^{-1}$ and $1637 \mathrm{~cm}^{-1}$ could have been observed by the carbonyl group. The presence of group $(\mathrm{NH})=\mathrm{O}$ may indicate that the cyclic peptides may have acted as stabilizing agents. The bands seen at $1042 \mathrm{~cm}^{-1}$ and $1009 \mathrm{~cm}^{-1}$ could be related to $\mathrm{C}-\mathrm{N}$ vibration of aliphatic amines. C. cylindracea based AgNPs indicate sharp peak at $1383 \mathrm{~cm}^{-1}$ and this could have been originated from $\mathrm{NO}_{3}{ }^{-}$ions in the $\mathrm{AgNO}_{3}$ solution (Edison et al., 2016).

Calcination process was applied for removing the high noise and augmenting intensity of peaks at $400^{\circ} \mathrm{C}$ for 2 hours. Diffraction peaks can be seen at $38.32^{\circ}$, $64.62^{\circ}, 77.62^{\circ}$ and $81.74^{\circ}$ (Figure 7). The particle size was found to be $22 \mathrm{~nm}$ by using Scherrer equation based on full width at half maximum belonging to $38.34^{\circ}$. As seen in Table 2, C, N, O, Mg, Al, Si, P, S, Cl were observed in the synthesized AgNPs. The elemental composition analysis of AgNPs according to the reduction agent source can be seen in Figure 8.

\section{Artificial Neural Network Study Results}

C. cylindracea extract was used for green synthesis of AgNPs and during the synthesis, the parameters like agitation time and rate, temperature, $\mathrm{pH}$ and concentration of $\mathrm{AgNO}_{3}$ and extract were studied and the experimental data were collected. Table 3 shows the data statistics of the study. The data was used for creating an artificial neural network by MATLAB.

The optimum hidden neuron number was found to be 17 when default settings (the percentages of training, validation and testing are 70,15 and $15 \%$, respectively, Levenberg-Marquardt backpropagation algorithm) were applied (Supplementary Material, Table 1). When the hidden neuron number was 17 , the $R^{2}$ values of training, validation and testing were found as 0.994327, 0.997549 and 0.991847 respectively. Also, the effects of data percentages were studied and the highest $\mathrm{R}^{2}$ values were found to be $0.994195,0.999989$ and 0.999664

Table 2. Results of composition analysis for Caulerpa cylindracea based silver nanoparticles.

\begin{tabular}{ccccccccccccccc}
\hline & \multicolumn{1}{c}{ Percentages of Elements } \\
\hline & $\mathrm{C}$ & $\mathrm{N}$ & $\mathrm{O}$ & $\mathrm{Na}$ & $\mathrm{Mg}$ & $\mathrm{Al}$ & $\mathrm{Si}$ & $\mathrm{P}$ & $\mathrm{S}$ & $\mathrm{Cl}$ & $\mathrm{Ag}$ & \\
C.cylindracea & 2.98 & 5.11 & 11.39 & 0.28 & - & 0.14 & 0.33 & 0.24 & 0.14 & 5.06 & 74.33 \\
\hline
\end{tabular}

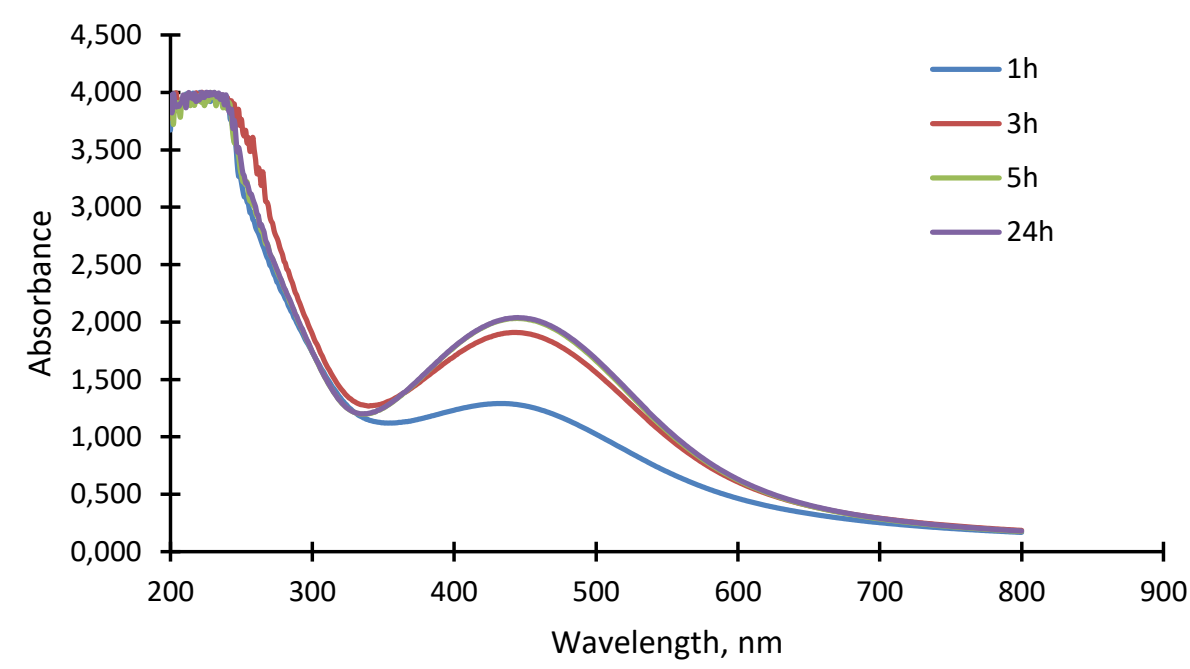

Figure 5. UV-Vis spectrum of Caulerpa cylindracea based silver nanoparticles. 
a

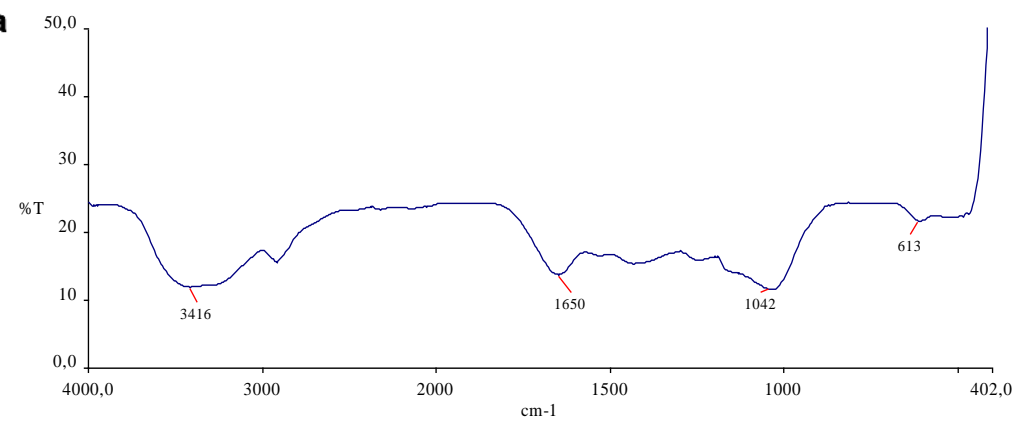

b

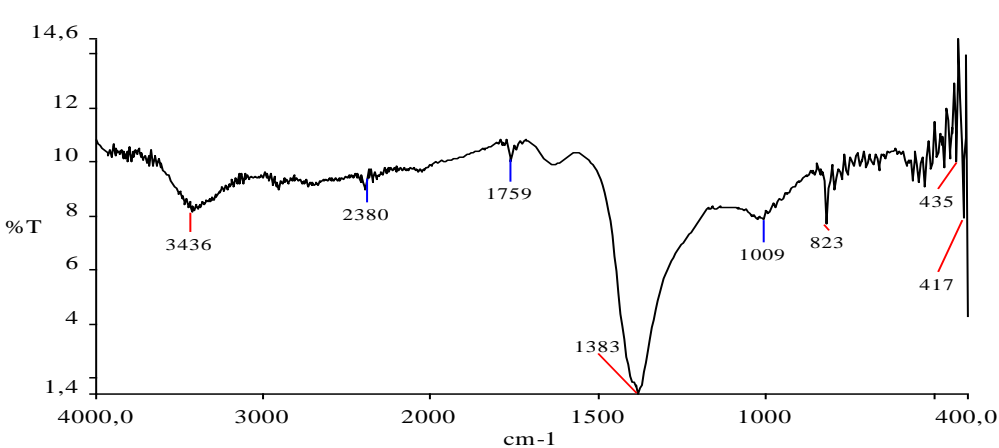

Figure 6. a) FT-IR spectrum of Caulerpa cylindracea. b) FT-IR spectrum of Caulerpa cylindracea based silver nanoparticles.

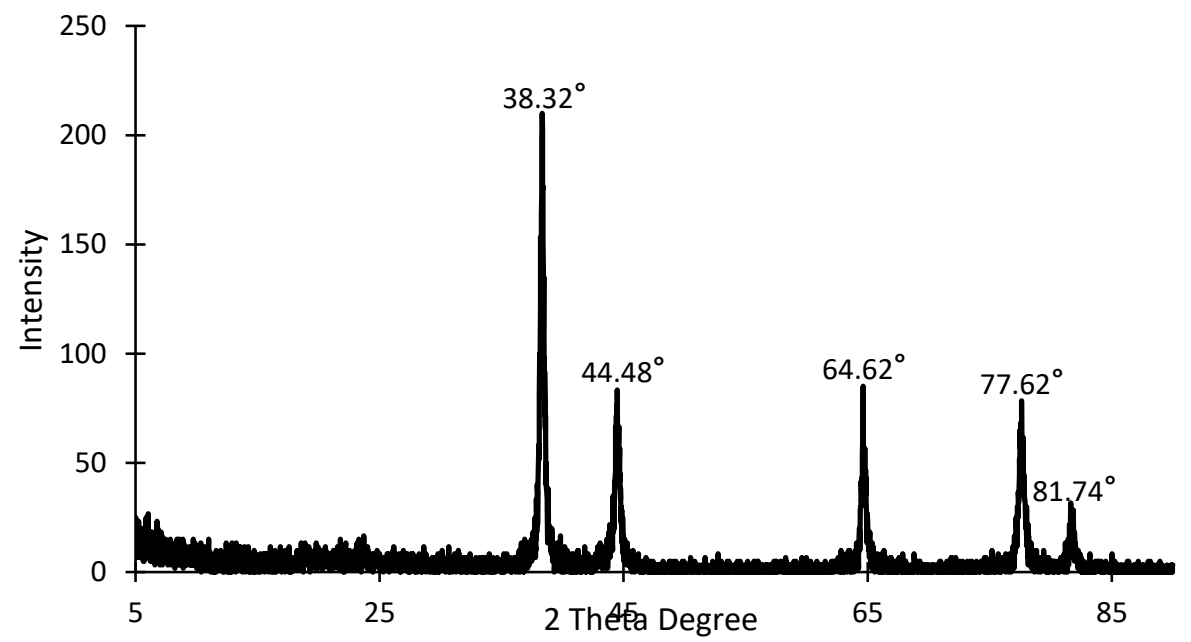

Figure 7. XRD spectrum of Caulerpa cylindracea based silver nanoparticles with calcination.

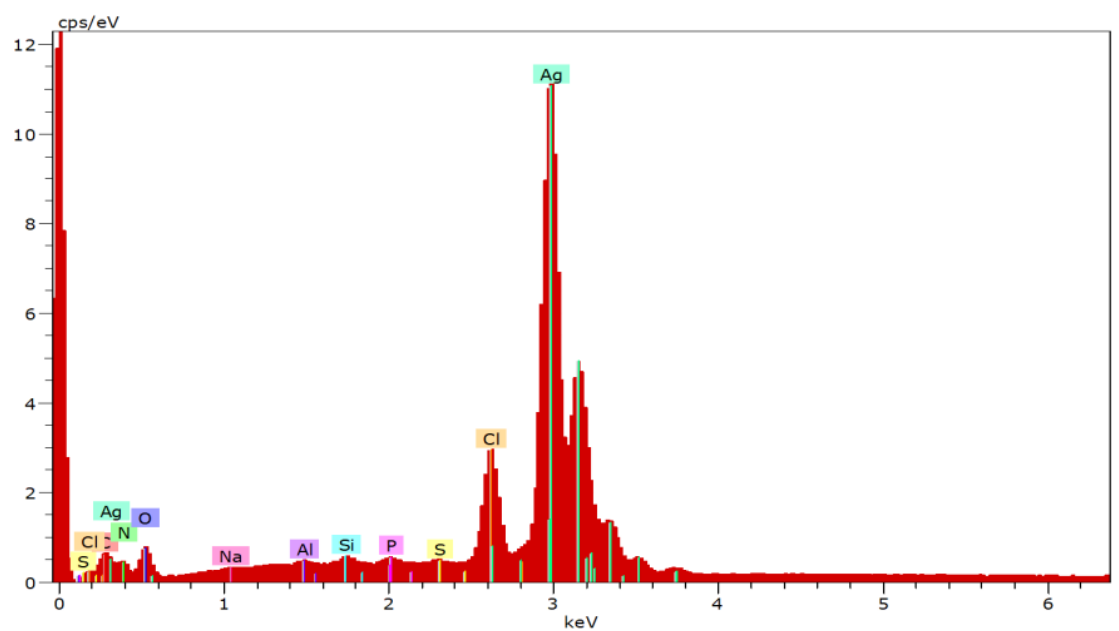

Figure 8. Elemental composition analysis of Caulerpa cylindracea based silver nanoparticles. 
when the percentages of training, validation and testing were 85,5 and 10 , respectively (Supplementary Material, Table 2). The performance of the 11 backpropagation algorithms was also studied in the previously optimised conditions (Supplementary Material, Table 3-4). The $R^{2}$ values of 3 of backpropagation algorithms were close to each other and these algorithms were Bayesian regularization backpropagation, scaled conjugate gradient backpropagation and Levenberg-Marquardt backpropagation algorithms. The $\mathrm{R}^{2}$ values of these backpropagations were found to be $0.9921,0.9919$ and 0.9918 , respectively. In order to test the efficiency of the created ANN, we drew the figures. Figure 9 shows $R$ value for Bayesian regularization backpropagation algorithm, other figures can be found as supplementary material (Supplementary Material Figure 1-2). As can be seen from these figures, very high correlations were obtained between experimental and ANN predicted results.

\section{Discussion}

In this study, C. cylindracea samples were collected from İzmir coastline and the biomass from this alien species was utilized for the green synthesis of AgNPs. In order to model experimental conditions related to the green synthesis of AgNPs, ANN, as an artificial intelligence method, was used. XRD, FT-IR and UV-Vis spectrometry were used for the characterization of the synthesized AgNPs.

Since $C$. cylindracea has been continuing its invasion in the Mediterranean Sea, alternative utilization methods should be evaluated for this species.

Table 3. The data statistics in the study

\begin{tabular}{lcc}
\hline Variables & Data Statistics Range & Mean \pm S.D. \\
\hline Agitation Time (min) & $0-360$ & $158 \pm 118.61$ \\
Agitation Rate $(\mathrm{rpm})$ & $0-400$ & $175 \pm 147.90$ \\
Temperature (o- $)$ & $25-85$ & $55 \pm 22.36$ \\
$\mathrm{pH}$ & $3-10.5$ & $6.94 \pm 1.76$ \\
$\mathrm{AgNO}_{3}$ Concentration $\left(\mathrm{mol}^{-1}\right)$ & $0.001-0.2$ & $0.03 \pm 0.03$ \\
Extract Concentration $\left(\mathrm{g} . \mathrm{mL}^{-1}\right)$ & $0.001-0.075$ & $0.4 \pm 0.25$ \\
Absorbance & $0.06-2.993$ & $0.448 \pm 0.247$ \\
\hline
\end{tabular}

Table 4. Performances of different backpropagation algorithms on the prediction of experimental values

\begin{tabular}{|c|c|c|c|c|c|c|c|c|}
\hline \multirow[b]{2}{*}{$\#$} & \multirow[b]{2}{*}{ Experimental } & \multicolumn{7}{|c|}{ ANN Algorithms } \\
\hline & & Trainbfg & Trainbr & Traincgb & Traincgf & Traincgp & Traingd & Traingdm \\
\hline 1 & 0.074 & 0.107 & 0.077 & 0.071 & 0.060 & 0.060 & 0.073 & 0.151 \\
\hline 2 & 0.084 & 0.100 & 0.082 & 0.080 & 0.060 & 0.060 & 0.081 & 0.128 \\
\hline 3 & 0.082 & 0.110 & 0.091 & 0.105 & 0.060 & 0.060 & 0.131 & 0.244 \\
\hline 4 & 0.098 & 0.105 & 0.091 & 0.100 & 0.060 & 0.060 & 0.117 & 0.187 \\
\hline 5 & 0.179 & 0.097 & 0.168 & 0.138 & 0.060 & 0.060 & 0.120 & 0.190 \\
\hline 6 & 0.193 & 0.216 & 0.223 & 0.288 & 0.060 & 0.060 & 0.106 & 0.302 \\
\hline 7 & 0.212 & 0.100 & 0.201 & 0.168 & 0.060 & 0.060 & 0.113 & 0.199 \\
\hline 8 & 0.430 & 0.669 & 0.615 & 0.445 & 0.122 & 0.060 & 0.698 & 0.278 \\
\hline 9 & 0.699 & 1.044 & 0.550 & 0.766 & 0.782 & 0.060 & 1.257 & 0.474 \\
\hline 10 & 0.474 & 0.388 & 0.415 & 0.162 & 0.062 & 0.060 & 0.445 & 0.129 \\
\hline 11 & 1.587 & 1.930 & 1.710 & 1.948 & 2.996 & 2.996 & 1.824 & 2.377 \\
\hline 12 & 1.964 & 2.530 & 2.217 & 2.296 & 2.994 & 2.927 & 2.461 & 1.604 \\
\hline 13 & 2.794 & 2.802 & 2.929 & 2.954 & 2.996 & 2.996 & 2.739 & 2.075 \\
\hline 14 & 0.081 & 0.103 & 0.087 & 0.103 & 0.060 & 0.060 & 0.143 & 0.160 \\
\hline 15 & 0.114 & 0.216 & 0.119 & 0.082 & 0.060 & 0.060 & 0.066 & 0.869 \\
\hline 16 & 0.074 & 0.131 & 0.182 & 0.069 & 0.060 & 0.109 & 0.078 & 0.070 \\
\hline 17 & 0.084 & 0.127 & 0.227 & 0.080 & 0.060 & 0.094 & 0.081 & 0.066 \\
\hline 18 & 0.082 & 0.141 & 0.264 & 0.085 & 0.060 & 0.122 & 0.089 & 0.068 \\
\hline 19 & 0.098 & 0.133 & 0.266 & 0.092 & 0.060 & 0.109 & 0.087 & 0.067 \\
\hline 20 & 0.179 & 0.125 & 0.408 & 0.170 & 0.062 & 0.130 & 0.099 & 0.077 \\
\hline 21 & 0.193 & 0.137 & 0.721 & 0.199 & 0.143 & 0.443 & 0.193 & 0.176 \\
\hline 22 & 0.212 & 0.126 & 0.456 & 0.196 & 0.069 & 0.157 & 0.113 & 0.087 \\
\hline 23 & 0.430 & 0.711 & 0.408 & 0.657 & 0.590 & 0.540 & 0.706 & 0.547 \\
\hline 24 & 0.699 & 1.037 & 0.417 & 0.580 & 0.660 & 0.867 & 0.704 & 0.657 \\
\hline 25 & 0.474 & 0.487 & 0.385 & 0.432 & 0.185 & 0.250 & 0.585 & 0.374 \\
\hline 26 & 1.587 & 2.360 & 0.513 & 1.728 & 1.911 & 2.022 & 1.992 & 1.783 \\
\hline 27 & 1.964 & 2.244 & 0.324 & 2.174 & 2.265 & 2.488 & 2.272 & 2.327 \\
\hline 28 & 2.794 & 2.842 & 0.612 & 2.979 & 2.967 & 2.869 & 2.957 & 2.948 \\
\hline 29 & 0.081 & 0.149 & 0.260 & 0.072 & 0.060 & 0.114 & 0.090 & 0.074 \\
\hline 30 & 0.114 & 0.101 & 0.144 & 0.231 & 0.060 & 0.284 & 0.078 & 0.061 \\
\hline
\end{tabular}




\section{trainbr}

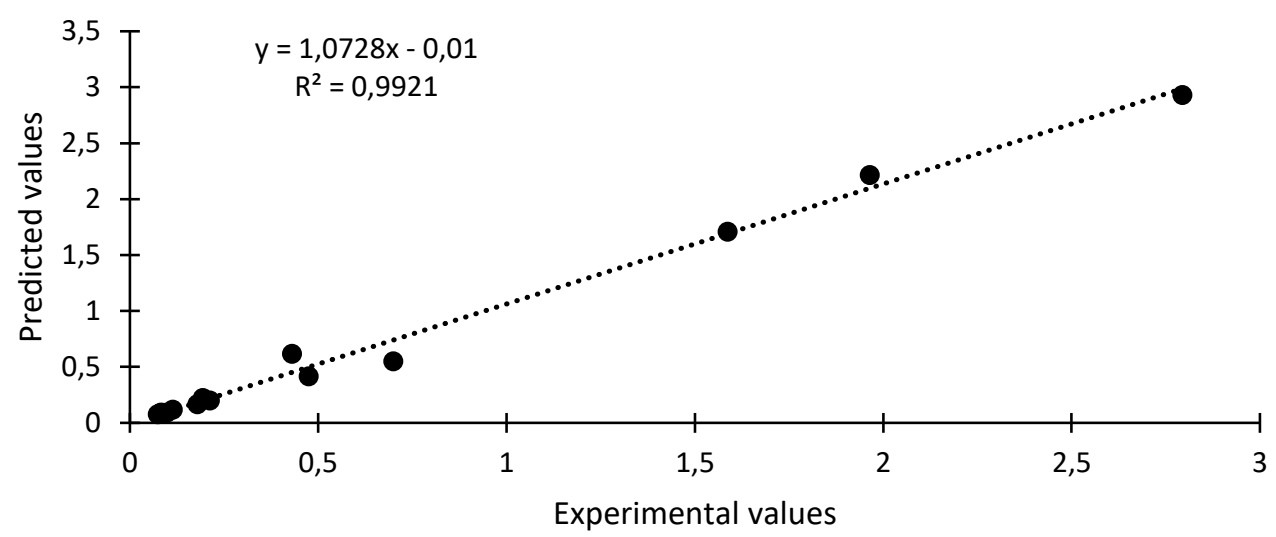

Figure 9. Comparison of experimental values with Artificial Neural Network predicted values (Trainbr: Bayesian regularization backpropagation)

There are many secondary metabolites in algae. Therefore, utilisation of these marine seaweeds is of importance for the evaluation of their biomasses. Biomasses or secondary metabolites of the marine seaweeds have so far been used in many different processes (Cavas \& Pohnert, 2010; Mollo et al., 2015). We have been following the invasion of $C$. cylindracea since 2004 off the İzmir coastlines (Turkey). Inasmuch as no decrease in the meadow size of $C$. cylindracea has so far been reported from İzmir coastline, its biomass can be used for the synthesis of AgNPs. It is very important to note that marine algae may change their composition based on the nutrient levels in marine ecosystems based on their collected sites. Moreover, secondary metabolites in marine algae can also be changed based on many different parameters. Therefore, basic biochemical tests should be carried out before synthesizing nanoparticules to obtain similar results or samples should be collected from same season. There are papers in the scientific literature related to the synthesis of AgNPs by using Caulerpa spp. Here we reviewed them. Kathiraven et al. (2015) studied the antibacterial activity of the synthesized AgNPs by Caulerpa racemosa. The authors characterized AgNPs through FT-IR, XRD, TEM and UV-Vis spectrometry. From the FT-IR results, they expressed that peptides may participate in the synthesis of AgNPs. TEM results indicated that morphology of synthesized AgNPs was spherical and their size was between 5-25 nm. They did antibacterial tests against $P$. mirabilis and $S$. aureus with different concentrations. They concluded that AgNPs can be synthesized by $C$. racemosa and the synthesized AgNPs are stable in solution because of capping agents like proteins within the extract. Edison et al. (2016) synthesized AgNPs and studied about the catalytic activity of these nanoparticles on the degradation of methylene blue. AgNPs were synthesized using Caulerpa racemosa. They used UV-Vis spectroscopy, EDS, FT-IR, $X R D$, and HR-TEM for the characterization of synthesized AgNPs. According to their results, the shape of synthesized AgNPs was distorted spherical and the size was $25 \mathrm{~nm}$. They tested the catalytic activity of synthesized AgNPs using UV-Vis spectroscopy. They reported that the reasonable mechanism for the AgNPs supported catalytic degradation of methylene blue was elucidated with the Langmuir-Hinshelwood model. According to this model, $\mathrm{NaBH}_{4}$ is an electron donor and hydrogen source. In addition to that AgNPs play a role as an electron transfer mediator between $\mathrm{BH}_{4}^{-}$ions and methylene blue (Edison et al., 2016). Aboelfetoh et al. (2017) synthesized AgNPs using Caulerpa serrulata and they studied reaction optimization, catalytic and antibacterial activity of synthesized AgNPs. They used FT-IR, XRD, HR-TEM and UV-Vis Spectroscopy for the characterization of synthesized AgNPs. Synthesized AgNPs size was $10 \pm 2 \mathrm{~nm}$. They examined $\mathrm{pH}$ values, contact time, extract concentration and temperature for reaction optimization. For optimization of degradation percentage of Congo red, they studied the effect of $\mathrm{NaBH}_{4}$ concentration, extract concentration and catalytic dosage. Aboelfetoh et al. (2017) investigated the effect of $\mathrm{pH}$ on the size of synthesized AgNPs. They found out that the size of AgNPs synthesized in acid medium was larger than the alkaline medium. They also reported that the kinetics of the reaction is increased with the increased temperature. Shabanzadeh et al. (2013) studied neural network modelling for the prediction of the size of AgNPs prepared by green method. They synthesized AgNPs using soluble starch. Their input parameters were the volume of $\mathrm{NaOH}$, temperature, starch and $\mathrm{AgNO}_{3}$ concentration and output parameter was the size of nanoparticles. For training, validation and testing steps they used 20, 5, 5 samples respectively. They found the hidden neuron number as $10 . R^{2}$ values of their best predictive model for training, validation and testing were $0.9839,0.9778$ and 0.9787, respectively (Shabanzadeh et al., 2013). Shabanzadeh et al. (2014) also worked neural network 
modelling for synthesis of AgNPs via montmorillonite/starch-chemical reduction method. Their input parameters were $\mathrm{AgNO}_{3}$ and $\mathrm{NaBH}_{4}$ concentration, temperature, the weight percentage of starch and output parameter was the size of silver nanoparticle in their ANN model. Their percentage of datasets for training, validation and testing were $70 \%$, $15 \%$ and $\% 15$, respectively. They found the number of the hidden neuron number as $10 . R^{2}$ values that they found for training, validation and testing were 0.9979, 0.9952 and 0.9984 respectively (Shabanzadeh et al., 2014).

\section{Conclusion}

Silver nanoparticles were synthesized using C. cylindracea extract and the experimental results were modelled with ANN. To optimise synthesis procedures, different parameters like temperature, agitation rate, $\mathrm{pH}$, concentration of $C$. cylindracea extract and $\mathrm{AgNO}_{3}$ were studied. After optimization optimum values for synthesis were found as $\mathrm{pH}=8$, at $85^{\circ} \mathrm{C}, 200 \mathrm{rpm}$ and concentration of $\mathrm{AgNO}_{3}$ and $\mathrm{C}$. cylindracea extract as 0.1 $\mathrm{M}$ and $0.01 \mathrm{~g} / \mathrm{mL}$. Size of silver nanoparticles were found as $22 \mathrm{~nm}$ using Scherrer equation. Other characterization methods also show formation of silver nanoparticles and capping agents as compatible with literature. The results modelled with ANN and the $R^{2}$ values of backpropagations were found to be 0.9921 , 0.9919 and 0.9918 , respectively. To conclude, very high correlations were obtained between experimental and ANN predicted results. The methods based on green chemistry are easy to apply and use of toxic chemicals is limited and these methods do not require the use of expensive tools. Utilization of $\mathrm{Al}$ in the field of chemistry is also important in terms of predicting possible outcomes before wet lab studies and reducing the workload. In conclusion, alien species contain many novel secondary metabolites to adapt to their new habitats as it was observed in invasive $C$. cylindracea. From the results of this paper, it is promising that AgNPs can be eco-friendly synthesized by using $C$. cylindracea. This paper can be a model study for utilisation of other alien species in the aquatic ecosystems.

\section{Ethical Statement}

The paper was originated from the master of science thesis of Yesim Yilmaz Abeska. Before starting her MSc.thesis, we applied Republic of Turkey, Ministry of Agriculture and Forestry, General Directorate of Nature Conservation and Parks on 19.07.2018 to collect Caulerpa cylindracea samples. Our application was approved by General Directorate of Nature Conservation and Parks.

\section{Funding Information}

There is no funding for the paper.

\section{Author Contribution}

YYA: Data Analysis, Formal Analysis, Methodology, Investigation, Writing -review and editing.

LC: Conceptualization, Supervision, Methodology, Resources, Visualization and Writing -original draft.

\section{Conflict of Interest}

The authors declare that they have no known competing financial or non-financial, professional, or personal conflicts that could have appeared to influence the work reported in this paper

\section{References}

Abboud, Y., Saffaj, T., Chagraoui, A., El Bouari, A., Brouzi, K., Tanane, O., \& Ihssane, B., (2014). Biosynthesis, characterization and antimicrobial activity of copper oxide nanoparticles (CONPs) produced using brown alga extract (Bifurcaria bifurcata). Applied Nanoscience, 4(5), 571-576. https://doi.org/10.1007/s13204-013-0233-x

Aboelfetoh, E.F., El-Shenody, R.A., \& Ghobara M.M., (2017). Eco-friendly synthesis of silver nanoparticles using green algae (Caulerpa serrulata): reaction optimization, catalytic and antibacterial activities. Environmental Monitoring and Assessment, 189(7), 349. https://doi.org/10.1007/s10661-017-6033-0

Ajitha, B., Divya, A., Harish, G., \& Sreedhara Reddy, P. (2013). The influence of silver precursor concentration on size of silver nanoparticles grown by soft chemical route. Research Journal of Physical Sciences, 2320, 4796.

Anastas, P., \& Eghbali, N., (2010). Green chemistry: principles and practice. Chemical Society Reviews, 39(1), 301-312. https://doi.org/10.1039/B918763

Arumugam, A., Karthikeyan, C., Hameed, A.S.H., Gopinath, K., Gowri, S., \& Karthika, V., (2015). Synthesis of cerium oxide nanoparticles using Gloriosa superba $L$. leaf extract and their structural, optical and antibacterial properties. Materials Science and Engineering C, 49, 408-415. https://doi.org/10.1016/j.msec.2015.01.042

Barwal, I., Ranjan, P., Kateriya, S., \& Yadav, S.C., (2011). Cellular oxido-reductive proteins of Chlamydomonas reinhardtii control the biosynthesis of silver nanoparticles. Journal of Nanobiotechnology, 9(1), 56. https://doi.org/10.1186/1477-3155-9-56

Bernardeau-Esteller, J., Marín-Guirao, L., Sandoval-Gil, J.M., García-Muñoz, R., Ramos-Segura, A., \& Ruiz, J.M., (2020). Evidence for the long-term resistance of Posidonia oceanica meadows to Caulerpa cylindracea invasion. Aquatic Botany, 160, 103167. https://doi.org/10.1016/j.aquabot.2019.103167Get

Cavas, L., \& Pohnert, G., (2010). The potential of Caulerpa spp. for biotechnological and pharmacological applications. In: J. Seckbach, R. Einav, \& A. Israel (Eds.), Seaweeds and their role in globally changing environments (pp. 385397). Springer.

Chakraborty, N., Pal, R., Ramaswami, A., Nayak, D., \& Lahiri, S., (2006). Diatom: a potential bio-accumulator of gold. Journal of Radioanalytical and Nuclear Chemistry, 270(3), 645-649. https://doi.org/10.1007/s10967-0060475-0

Dande, P., \& Samant, P., (2018). Acquaintance to Artificial Neural Networks and use of artificial intelligence as a 
diagnostic tool for tuberculosis: A review. Tuberculosis, 108, 1-9. https://doi.org/10.1016/j.tube.2017.09.006

Darroudi, M., Ahmad, M.B., Zamiri, R., Zak, A.K., Abdullah, A.H., \& Ibrahim, N.A. (2011). Time-dependent effect in green synthesis of silver nanoparticles. International journal of nanomedicine, 6, 677. https://doi.org/10.2147/IJN.S17669

Davis, T.A., Volesky, B., \& Mucci, A., (2003). A review of the biochemistry of heavy metal biosorption by brown algae. Water Research, 37(18), 4311-4330. https://doi.org/10.1016/S0043-1354(03)00293-8

Dodoo-Arhin, D., Asiedu, T., Agyei-Tuffour, B., Nyankson, E., Obada, D., \& Mwabora, J.M., (2020). Photocatalytic degradation of Rhodamine dyes using zinc oxide nanoparticles. Materials Today: Proceedings, 6(1), 258267. https://doi.org/10.1016/j.matpr.2020.04.597

Edison, T.N.J.I., Atchudan, R., Kamal, C., \& Lee, Y.R., (2016). Caulerpa racemosa: a marine green alga for eco-friendly synthesis of silver nanoparticles and its catalytic degradation of methylene blue. Bioprocess and Biosystems Engineering, 39(9), 1401-1408. https://doi.org/10.1007/s00449-016-1616-7

Fayaz, A.M., Balaji, K., Kalaichelvan, P.T., \& Venkatesan, R. (2009). Fungal based synthesis of silver nanoparticlesan effect of temperature on the size of particles. Colloids and Surfaces B: Biointerfaces, 74(1), 123-126. https://doi.org/10.1016/j.colsurfb.2009.07.002

González-Ballesteros, N., González-Rodríguez, J.B., RodríguezArgüelles, M.C., \& Lastra, M., (2018). New application of two Antarctic macroalgae Palmaria decipiens and Desmarestia menziesii in the synthesis of gold and silver nanoparticles. Polar Science, 15, 49-54. https://doi.org/10.1016/j.polar.2017.10.004

Htwe, Y.Z.N., Chow, W.S., Suda, Y., \& Mariatti, M. (2019). Effect of silver nitrate concentration on the production of silver nanoparticles by green method. Materials Today: Proceedings, 17, 568-573. https://doi.org/10.1016/j.matpr.2019.06.336

Iravani, S., (2011). Green synthesis of metal nanoparticles using plants. Green Chemistry, 13(10), 2638-2650. https://doi.org/10.1039/C1GC15386B

Jamkhande, P.G., Ghule, N.W., Bamer, A.H., \& Kalaskar, M.G., (2019). Metal nanoparticles synthesis: An overview on methods of preparation, advantages and disadvantages, and applications. Journal of Drug Delivery Science and Technology, 53, 101174. https://doi.org/10.1016/j.jddst.2019.101174

Janardhanan, R., Karuppaiah, M., Hebalkar, N., \& Rao, T.N. (2009). Synthesis and surface chemistry of nano silver particles. Polyhedron, 28(12), 2522-2530. https://doi.org/10.1016/j.poly.2009.05.038

Jia, C.J., \& Schüth, F., (2011). Colloidal metal nanoparticles as a component of designed catalyst. Physical Chemistry Chemical Physics, 13(7), 2457-2487. https://doi.org/10.1039/COCP02680H

Kathiraven, T., Sundaramanickam, A., Shanmugam, N., \& Balasubramanian, T., (2015). Green synthesis of silver nanoparticles using marine algae Caulerpa racemosa and their antibacterial activity against some human pathogens. Applied Nanoscience, 5(4), 499-504. https://doi.org/10.1007/s13204-014-0341-2

Katta, V.K.M., \& Dubey, R.S., (2020). Green synthesis of silver nanoparticles using Tagetes erecta plant and investigation of their structural, optical, chemical and morphological properties. Materials Today: Proceedings, https://doi.org/10.1016/j.matpr.2020.02.809

Khalil, M.M., Ismail, E.H., El-Baghdady, K.Z., \& Mohamed, D. (2014). Green synthesis of silver nanoparticles using olive leaf extract and its antibacterial activity. Arabian Journal of Chemistry, 7(6), 1131-1139. https://doi.org/10.1016/j.arabjc.2013.04.007

Kharissova, O.V., Dias, H.R., Kharisov, B.I., Pérez, B.O., \& Pérez, V.M.J., (2013). The greener synthesis of nanoparticles. Trends in Biotechnology, 31(4), 240-248. https://doi.org/10.1016/j.tibtech.2013.01.003

Klein, J., \& Verlaque, M., (2008). The Caulerpa racemosa invasion: A critical review. Marine Pollution Bulletin, 56(2), 205-225.

https://doi.org/10.1016/j.marpolbul.2007.09.043

Kushnerova, N.F., Fomenko, S.E., Sprygin, V.G., Kushnerova, T.V., Khotimchenko, Y.S., Kondrat'eva, E.V., \& Drugova, L.A., (2010). An extract from the brown alga Laminaria japonica: a promising stress-protective preparation. Russian Journal of Marine Biology, 36(3), 209-214. https://doi.org/10.1134/S1063074010030077

Liu, H., Zhang, H., Wang, J., \& Wei, J. (2020). Effect of temperature on the size of biosynthesized silver nanoparticle: deep insight into microscopic kinetics analysis. Arabian Journal of Chemistry, 13(1), 1011-1019. https://doi.org/10.1016/j.arabjc.2017.09.004

Lloyd, J.R., Byrne, J.M., \& Coker, V.S., (2011). Biotechnological synthesis of functional nanomaterials. Current Opinion in Biotechnology, 22(4), 509-515. https://doi.org/10.1016/j.copbio.2011.06.008

Mahdavi, M., Namvar, F., Ahmad, M., \& Mohamad, R., (2013). Green biosynthesis and characterization of magnetic iron oxide $\left(\mathrm{Fe}_{3} \mathrm{O}_{4}\right)$ nanoparticles using seaweed (Sargassum muticum) aqueous extract. Molecules, 18(5), 5954-5964. https://doi.org/10.3390/molecules18055954

Mandlik, V., Bejugam, P.R., \& Singh, S., (2016). Application of artificial neural networks in modern drug discovery. In: M. Puri, Y. Pathak, V. Sutariya, S. Tipparaju, \& W. Moreno (Eds.), Artificial Neural Network for Drug Design, Delivery and Disposition (pp. 123-139). Academic Press.

Martinez-Gutierrez, F., Olive, P.L., Banuelos, A., Orrantia, E., Nino, N., Sanchez, E.M., Ruiz, F., Bach, H., \& Av-Gay, Y., (2010). Synthesis, characterization, and evaluation of antimicrobial and cytotoxic effect of silver and titanium nanoparticles. Nanomedicine: Nanotechnology, Biology and Medicine, 6(5), 681-688.

https://doi.org/10.1016/j.nano.2010.02.001

Mahiuddin, M., Saha, P., \& Ochiai, B. (2020). Green Synthesis and Catalytic Activity of Silver Nanoparticles Based on Piper chaba Stem Extracts. Nanomaterials, 10(9), 1777. https://doi.org/10.3390/nano10091777

Mert, N., Topcam, G., \& Cavas, L., (2014). RP-HPLC optimization of econea by using artificial neural networks and its antifouling performance on the Turkish coastline. Progress in Organic Coatings, 77(3), 627-635. https://doi.org/10.1016/j.porgcoat.2013.11.027

Mizuno, M., Nishitani, Y., Tanoue, T., Matoba, Y., Ojima, T., Hashimoto, T., \& Kanazawa, K., (2009). Quantification and localization of fucoidan in Laminaria japonica using a novel antibody. Bioscience, Biotechnology, and Biochemistry, 73(2), 335-338. https://doi.org/10.1271/bbb.80542

Mollo, E., Cimino, G., \& Ghiselin, M.T., (2015). Alien biomolecules: a new challenge for natural product 
chemists. Biological Invasions, 17(3), 941-950. https://doi.org/ 10.1007/s10530-014-0835-6

Momeni, S., \& Nabipour, I., (2015). A simple green synthesis of palladium nanoparticles with Sargassum alga and their electrocatalytic activities towards hydrogen peroxide. Applied Biochemistry and Biotechnology, 176(7), 19371949. https://doi.org/10.1007/s12010-015-1690-3

Nadagouda, M.N., \& Varma, R.S., (2008). Green synthesis of silver and palladium nanoparticles at room temperature using coffee and tea extract. Green Chemistry, 10(8), 859-862. https://doi.org/10.1039/B804703K

Niu, Z., Feng, W., Huang, H., Wang, B., Chen, L., Miao, Y., \& Su, S., (2020). Green synthesis of a novel $\mathrm{Mn}-\mathrm{Zn}$ ferrite/biochar composite from waste batteries and pine sawdust for $\mathrm{Pb}^{2+}$ removal. Chemosphere, 126529. https://doi.org/10.1016/j.chemosphere.2020.126529

Philip, D., (2010). Green synthesis of gold and silver nanoparticles using Hibiscus rosa sinensis. Physica E: Low-dimensional Systems and Nanostructures, 42(5), 1417-1424. https://doi.org/10.1016/j.physe.2009.11.08

Piazzi, L., \& Balata, D., (2008). The spread of Caulerpa racemosa var. cylindracea in the Mediterranean Sea: an example of how biological invasions can influence beta diversity. Marine Environmental Research, 65(1), 50-61. https://doi.org/10.1016/j.marenvres.2007.07.002

Pivetta, T., Isaia, F., Trudu, F., Pani, A., Manca, M., Perra, D., Amato, F., \& Havel, J., (2013). Development and validation of a general approach to predict and quantify the synergism of anti-cancer drugs using experimental design and artificial neural networks. Talanta, 115, 8493. https://doi.org/10.1016/j.talanta.2013.04.031

Ramkumar, V.S., Pugazhendhi, A., Prakash, S., Ahila, N.K., Vinoj, G., Selvam, S., Kumar, G., Kannapiram, E., \& Rajendran, R.B. (2017). Synthesis of platinum nanoparticles using seaweed Padina gymnospora and their catalytic activity as PVP/PtNPs nanocomposite towards biological applications. Biomedicine \& Pharmacotherapy, 92, 479-490.

https://doi.org/10.1016/j.biopha.2017.05.076

Ramsden, J., (2018). Applied nanotechnology: the conversion of research results to products. William Andrew.

Rao, M.D., \& Pennathur, G., (2017). Green synthesis and characterization of cadmium sulphide nanoparticles from Chlamydomonas reinhardtii and their application as photocatalysts. Materials Research Bulletin, 85, 6473. https://doi.org/10.1016/j.materresbull.2016.08.049

Ravikumar, S., Gnanadesigan, M., Suganthi, P., \& Ramalakshmi, A., (2010). Antibacterial potential of chosen mangrove plants against isolated urinary tract infectious bacterial pathogens. International Journal of Medical Sciences, 2(3), 94-99.

https://doi.org/10.5897/IJMMS.9000023

Sakulwech, S., Lourith, N., Ruktanonchai, U., \& Kanlayavattanakul, M., (2018). Preparation and characterization of nanoparticles from quaternized cyclodextrin-grafted chitosan associated with hyaluronic acid for cosmetics. Asian Journal of Pharmaceutics, 13(5), 498-504.

https://doi.org/10.1016/j.ajps.2018.05.006Get

Sathishkumar, M., Sneha, K., Won, S.W., Cho, C.W., Kim, S., \& Yun, Y.S. (2009). Cinnamon zeylanicum bark extract and powder mediated green synthesis of nano-crystalline silver particles and its bactericidal activity. Colloids and Surfaces B: Biointerfaces, 73(2), 332-338. https://doi.org/10.1016/j.colsurfb.2009.06.005
Sen, I.K., Maity, K., \& Islam, S.S., (2013). Green synthesis of gold nanoparticles using a glucan of an edible mushroom and study of catalytic activity. Carbohydrate Polymers, 91(2), 518-528.

https://doi.org/10.1016/j.carbpol.2012.08.058

Shabanzadeh, P., Senu, N., Shameli, K., \& Ismail, F., (2013). Application of Artificial Neural Network (ANN) for Prediction Diameter of Silver Nanoparticles Biosynthesized in Curcuma Longa Extract. Digest Journal of Nanomaterials and Biostructures, 8(3), 1133-1144.

Shabanzadeh, P., Yusof, R., \& Shameli, K., (2014). Neural network modelling for prediction size of silver nanoparticles in montmorillonite/starch synthesis by chemical reduction method. Digest Journal of Nanomaterials and Biostructures, 9(4), 1699-1711.

Shankar, P.D., Shobana, S., Karuppusamy, I., Pugazhendhi, A., Ramkumar, V.S., Arvindnarayan, S., \& Kumar, G., (2016). A review on the biosynthesis of metallic nanoparticles (gold and silver) using bio-components of microalgae: Formation mechanism and applications. Enzyme and Microbial Technology, 95, 28-44. https://doi.org/10.1016/j.enzmictec.2016.10.015

Sharma, V.K., Yngard, R.A., \& Lin, Y., (2009). Silver nanoparticles: green synthesis and their antimicrobial activities. Advances in Colloid and Interface Science, 145(1-2), 83-96. https://doi.org/10.1016/j.cis.2008.09.002

Shi, L., Shan, J., Ju, Y., Aikens, P., \& Prud'homme, R.K., (2012). Nanoparticles as delivery vehicles for sunscreen agents. Colloids and Surfaces A: Physicochemical and Engineering Aspects, 396, 122-129. https://doi.org/10.1016/j.colsurfa.2011.12.053

Singh, M., Kalaivani, R., Manikandan, S., Sangeetha, N., \& Kumaraguru, A.K., (2013). Facile green synthesis of variable metallic gold nanoparticle using Padina gymnospora, a brown marine macroalga. Applied Nanoscience. 3(2), 145-151. https://doi.org/10.1007/s13204-012-0115-7

Singh, A.K., (2015). Engineered nanoparticles: structure, properties and mechanisms of toxicity. Academic Press.

Singh, P., Kim, Y. J., Wang, C., Mathiyalagan, R., \& Yang, D.C., (2016). Weissella oryzae DC6-facilitated green synthesis of silver nanoparticles and their antimicrobial potential. Artificial Cells, Nanomedicine, and Biotechnology, 44(6), 1569-1575. https://doi.org/10.3109/21691401.2015.1064937

Song, J.Y., Jang, H.K., \& Kim, B.S. (2009). Biological synthesis of gold nanoparticles using Magnolia kobus and Diopyros kaki leaf extracts. Process Biochemistry, 44(10), 11331138. https://doi.org/10.1016/j.procbio.2009.06.005

The MatWorks (2016b) MATLAB User's Guide. The MatWorks, Inc., Natick, MA.

Vázquez-Luis, M., Sanchez-Jerez, P., \& Bayle-Sempere, J.T., (2008). Changes in amphipod (Crustacea) assemblages associated with shallow-water algal habitats invaded by Caulerpa racemosa var. cylindracea in the western Mediterranean Sea. Marine Environmental Research, 65(5), 416-426. https://doi.org/10.1016/j.marenvres.2008.01.006

Velusamy, P., Kumar, G.V., Jeyanthi, V., Das, J., \& Pachaiappan, R., (2016). Bio-inspired green nanoparticles: synthesis, mechanism, and antibacterial application. Toxicological Research, 32(2), 95. https://doi.org/10.5487/TR.2016.32.2.095 
Wang, J., \& Chen, C., (2009). Biosorbents for heavy metals removal and their future. Biotechnology Advances, 27(2), 195-226.

https://doi.org/10.1016/j.biotechadv.2008.11.002
Yu, X., Ye, C., \& Xıang, L., (2016). Application of artificial neural network in the diagnostic system of osteoporosis. Neurocomputing, 214, 376-381.

https://doi.org/10.1016/j.neucom.2016.06.023 